\title{
Fibromialgia - interfaces com as LER/DORT e considerações sobre sua etiologia ocupacional
}

\author{
Fibromyal gia - interfaces to RSI \\ and considerations about work etiology
}

Tatiana Teixeira Álvares ${ }^{1}$

M aria Elizabeth Antunes Lima ${ }^{2}$

${ }^{1}$ Departamento de Fisioterapia, Faculdade Pitágoras. Rua Timbiras 1375, Funcionários. 30140060 Belo Horizonte M G. tatianaalvares@yahoo.com.br ${ }^{2}$ Departamento de Psicologia, Faculdade de Filosofia e Ciências H umanas, Universidade Federal de M inas Gerais.
Abstract Two groups of patients, one presenting symptoms of fibromyalgia and previous diagnostics of RSI (Repetitive Strain Injury), and the other only with fibromyalgia were compared in attempt to comprehend the relations between these two conditions and also between fibromyalgia and work. It was used the biographical method, with detailed interviews and creation of clinical casesfrom six patients with fibromyalgia, three of each group. It was noticed that patients from the first group showed a clear relationship between the disease's evolution and the overload of work. The patients of second group showed some of the symptoms since childhood or adolescence that becameworse after they had suffered an emotionally strong impact. Also, these patients reported cases of similar symptoms of fibromyalgia in their families, on the contrary of the first group. It was conclude that in some patients with fibromyalgia, the overload work is an important etiologic factor, and could be preceded by RSI I In these cases the diagnosis of fibromyalgia could be used as an attempt of disassociate the relation between symptoms and the work, preventing the worker to get social security benefits.

Key words Fibromyalgia, RSI, Work
Resumo Através da comparação de dois grupos de pacientes, um de portadores de fibromialgia com diagnóstico anterior de LER/DORT e outro com diagnóstico apenas defibromial gia, tentou-secompreender as relações entre as duas condições etambém entre a fibromialgia e o trabalho. Foi utilizado o método biográfico, através de entrevistas em profundi dadee construção de casos clínicos de seis pacientes portadoras defibromialgia, sendo três de cada grupo. Observou-se que as pacientes do primeiro grupo apresentaram clara relação entre a evolução da doença ea sobrecarga ocupacional. Já as pacientes do segundo grupo apresentaram alguns dos sintomas desde infância ou adolescência, sendo que estes ficaram ainda mais intensos após vivenciarem experiências de forte impacto emocional. Além disso, essas pacientes relatavam história familiar de sintomas semel hantes aos da fibromialgia, ao contrário do primeiro grupo. Conduiuseque, em al guns pacientes portadores de fibromialgia, a sobrecarga ocupacional constitui um importante fator etiológico, podendo ser precedida pelas LER/D ORT, e, nesses casos, o diagnóstico de fibromial gia pode estar sendo utilizado como uma tentativa de desvincular o nexo dos sintomas com o trabalho, impedindo o trabalhador de ter acesso aos benefícios previdenciários.

Palavras-chave Fibromialgia, LER/DORT, Trabalho 
Introdução

Os pacientes portadores de dores crônicas e generalizadas, sobretudo quando apresentam também al gumas outras características como alterações do sono, gastrointestinais, transtornos de humor e outras, podem se deparar com um diagnóstico bastante comum atualmente: 0 de fibromialgia. Apesar dos critérios diagnósticos terem sido estabelecidos apenas em 1990, os sintomas dessa patologia já se apresentavam, sob diversas denominações, há mais de trinta anos.

Trata-se de uma condição que é alvo de estudos em várias especialidades médicas, pois apre senta um conjunto de sintomas que a caracterizam como uma síndrome. Os fatores etiológicos são diversos, embora não estejam total mentedesvendados, eos tratamentos propostos ainda pouco eficazes, sendo consideradas, inclusive, diversas abordagens multidisciplinares sem quesepossa garantir um sucesso absoluto do tratamento.

0 diagnóstico de fibromialgia tem sucedido e, não raro substituído, o de lesão por esforços repetitivos (LER) ou distúrbios osteomusculares relacionados ao trabalho (DORT). Tal fato chamou nossa atenção, pois pacientes que tinham diagnósticos de distúrbios relacionados à sobrecarga de trabalho, ao serem "transformados" em fibromiálgicos, perdiam o nexo causal entre seus sintomas e a atividade profissional exercida.

Diante de um diagnóstico em que os fatores etiológi cos ainda não foram completamentedesvendados, al gumas interrogações tornam-seinevitáveis: o trabal ho podecontribuir para o surgimento da fibromialgia? As LER/DORT podem ocorrer concomitantemente à fibromialgia, ou poderiam constituir-se em um fator predisponente? AsLER/DORT poderiam evoluir para um quadro de fibromial gia? Enfim, em que consiste efetivamente essa última entidade nosológica e em que ela se diferencia das LER/DORT?

É dentro desse contexto que pretendemos explorar o tema da fibromialgia, enfocando, de forma especial, suas possíveis relações com o trabalho, através de um estudo que deu origem a uma dissertação de mestrado.

Fibromialgia

Caracterização e etiopatogenia

A fibromialgia tem sido entendida como uma condição crônica que acomete uma proporção de 6 a 10 mulheres para cada homem ${ }^{1}$, consistin- do em dor generalizada com mais de três meses de duração (definida como dor em ambos os lados, esquerdo e direito do corpo, bem como acima e abaixo da cintura), dor axial (dor na coluna cervical, torácica ou lombar, ou no tórax anterior), e dor à palpação de pelo menos onze de dezoito pontos específicos do corpo ${ }^{2,3}$. Além dessas características essenciais para a sua classificação, têm sido identificados, como manifestações clínicas da fibromialgia, sintomas como fadiga e sono não reparador, rigidez matinal, síndrome do cólon irritável ( $\mathrm{SCl}$ ), fenômeno de Raynaud, cefaléias, parestesias, palpitações, sensação de aumento do volume articular, síndrome uretral, dispepsia não-ulcerosa, tensão pré-menstrual, incômodo psicológico como depressão e ansi edade, equeixas cognitivas como problemas dememóriae incapacidade para concentrar-se $\mathrm{s}^{4,5}$.

Embora o American College of Rheumatology tenha estabelecido os critérios diagnósticos para a fibromial gia em $1990^{2}$, posteriormente validados para a população brasileira ${ }^{3}$, tal condição continua a ter uma caráter controverso, seja pelos diagnósticos equivocados que geralmente a precedem ou acompanham, seja pelo tratamento segmentado e pouco eficaz que seus portadores recebem.

As causas da fibromialgia ainda não foram totalmente desvendadas. Alguns estudos mostram a relação do início dos sintomas com um evento específico, como acidente automobilístico, sobrecarga no trabalho, local de trabalho ergonomicamentedeficitário, lesão por esforço repetitivo e infecção ${ }^{6-9}$. Waylonis et al. ${ }^{7}$ fizeram referência a pesquisas que apontam para uma he rança autossômica dominante como uma das causas dessa síndrome.

Riberto $^{10}$, ao realizar a revisão na literatura para comparar as manifestações clínicas de pacientes portadores de fibromial gia traumática e não-traumática, observou que tanto os traumas físicos como os emocionais têm sido relacionados com o aparecimento de dor generalizada em relatos esporádicos da literatura, mas não é raro que pacientes relacionem seus sintomas a situações específicas de estresse emocional ou de sobrecarga do aparelho locomotor, como quando são submetidos a esforços, repetições, posturas inadequadas ou lesões diretas dos ossos e de partes moles.

Paiva11 ressaltou a importância do diagnóstico para o paciente, dizendo que: [...] quando 0 paciente recebe o diagnóstico de FM o manejo torna-seum pouco maisfácil, provavelmentepor uma melhor compreensão da natureza benigna, porém 
crônica, do problema; há uma redução na procura de diagnósticos diferenciais por meio da solicitação exagerada de exames e um comprometimento maior do paciente no tratamento.

Após uma conferência sobrea neurociênciae a endocrinologia da fibromialgia em 1996, Pillemer et al. ${ }^{12}$ concluíram que: A fibromialgia tem sido considerada por muitos como uma síndrome difusa enebulosa que está "na cabeça do paciente". Existem muitas evidências de que estas impressões têm em si um elemento deverdade - não pelo descaso com que tratam os pacientes com fibromialgia, mas pelo nível fisiológico. M uita da sintomatologia da fibromialgia é familiar em outros contextos a pesquisadores de áreas da dor, neurociência, endocrinologia e sono, particularmente quando se consideram os mecanismos mediados pelas vias centrais.

Muhammad Yunus ${ }^{13}$ propôs um modelo para a patofisiologia da fibromialgia, no qual sugeriu que o defeito primário na fibromial gia é uma disfunção complexa neuro-hormonal, levando a mecanismos centrais aberrantes de dor que, sozinhos, poderiam provocar o quadro em muitos pacientes.

Wolfe ${ }^{9}$ relata também a existência de um crescentenúmero de pacientes queatribuem o início da fibromial gia a um evento específico de trauma ou acidente, mas identifica, na literatura, autores que admitem e outros que nunca estabele ceram tal relação. Pela falta de clareza e acordo quanto ao aspecto diagnóstico e patogênico da fibromialgia, segundo 0 autor, não raro esses pacientes são recebidos com insatisfação pelos médicos, pois estes se vêem envolvidos em aspectos legais referentes à doença com os quais ainda não sabem lidar adequadamente.

\section{A fibromialgia, as LER/DORT e o contexto de trabalho}

A clínica mostra cada vez mais pacientes fibromiálgicos com alguma queixa de sobrecarga ocupacional, mas os poucos estudos encontrados na literatura apontam somente para uma possível "evolução" de sintomas locais, típicos da LER/DORT, para sintomas generalizados, enfocando as possíveis alterações anátomo-fisiológicas envolvidas nesse processo. Esses estudos não abordam a situação de trabalho e nem seus impactos na saúde mental desses indivíduos, fatores de relevância pois, como já mencionado por vários autores, o início dos sintomas pode estar relacionado a uma condição de estresse físico e/ ou psicológico.
A falta de consenso sobreo diagnóstico e tratamento da fibromialgia extrapola os limites da clínica e da pesquisa. 0 fato desta condição surgir também em contextos de trabalho exige um posicionamento do sistema de saúde eben efícios quanto à sua classificação, o que não tem acontecido. Em 1998, foi publicada uma Ordem de Serviço do INSS ${ }^{14}$ para aprovar a Norma Técnica sobre as LER/DORT, dividida em duas seções. A primeira trata da atualização clínica das LER/ DORT e, a segunda, da norma técnica de avaliação da incapacidade laborativa para esse diagnóstico. Na seção I, ao discorrer sobre o diagnóstico das LER/DORT, a fibromial gia foi incluída no item 6.3 nos seguintes termos: As fibromialgias são predominantes em certos pacientes com LER, como os telefonistas. N estes profissionais predominam as dores difusas, sem lesões específicas demonstráveis. [...] pode-se concluir que a fibromialgia é uma doença complexa que pode ter ou não um componenteocupacional importante. Cabe ao médico avaliar a existência do componente.

Entretanto, na seção II do mesmo documento, a fibromial gia foi classificada no item 2.3.2.5 como uma "patologia não ocupacional", revelando a ambiguidade com a qual o tema tem sido tratado pelos órgãos que deveriam, no entanto, orientar os profissionais de saúde.

Tal posicionamento (ou falta de posicionamento) do IN SS quanto a uma possível etiologia ocupacional da fibromialgia nos remete à problemática das LER/DORT, cuja evolução tem sido também baseada na tentativa de descaracterização do seu nexo com o trabalho. Verthein e Gomez ${ }^{15}$ observam que essas afecções "tornam-se, a partir dos anos 90, cada vez mais referendadas pela neuropsiquiatria" equeessa referência "apresenta-se como uma armadilha, servindo à instituição previdenciária para negar" seu nexo "com o trabalho". Os autores expõem a trajetória das políticas previdenciárias, culminando em mudanças na sua estrutura que "mantêm as mesmas diretrizes básicas quanto ao aumento das taxas de contribuição eà redução dos ben efícios", concluindo: [...] que esse caminho das reformas deixa a desejar quanto aos direitos trabalhistas sociais conquistados pelos trabalhadores ao longo da sua história e tem excluído, da globalizada reestruturação produtiva, não só os trabalhadores que adoecem, mas a própria doença do trabalho.

Na Austrália, as LER/DORT também passaram por toda essa descaracterização do nexo, sendo que tal problema foi abordado por autores que "articulam uma rede discursiva de conceitos, mitos, valores e estratégias de ação" ${ }^{15}$, gerando 0 
que denominam neuropsiquiatrização das LER, $\mathrm{e}$ transformando essa condição de etiologia física em psíquica. Nesse processo, as LER têm sido apontadas como produto da iatrogenia, sugerindo que as medidas preventivas poderiam estar levando ao agravamento do problema. Os trabaIhadores teriam uma "neurose profissional" e estariam, na verdade, em busca de benefícios. Esse tipo de análise exclui por completo o trabalho na etiologia das LER, e, o mais complicado, transforma o trabalhador de vítima em explorador, ou seja, eleéacusado de simular um quadro osteomuscular para espoliar a previdência.

Conforme dissemos, o início dos sintomas da fibromial gia muitas vezes é precedido ou concomitante a um episódio de estresse físico ou psicológico, dor localizada ou mesmo infecção severa ${ }^{4,1}$. Assim como Reilly ${ }^{6}$, entendemos quetais problemas podem ser associados ao contexto de trabalho, pois segundo o autor, um número cada vez maior [de pacientes] atribui a doença à ergonomia deficiente no local de trabalho, ou mesmo à atividade, geralmenteenvolven do a sustentação de posturas que solicitam a coluna lombar ou cervical, ou movimentos repetitivos das mãos e punhos.

Para esse autor, sintomas isolados ou em segmentos do corpo podem ser considerados como formas regionais de fibromialgia e, em vários casos, precedem aqueles mais generalizados, ou seja, os que fazem parte dos critérios de diagnóstico da doença. Ele considera o problema da fibromialgianos contextos detrabal ho como complexo e multifatorial.

Já Littlejohn ${ }^{16}$ e H elfenstein e Feldman ${ }^{17}$ são radicalmente contra qualquer aproximação da fibromialgia com o fator ocupacional, atribuindo essa síndrome somente a fatores psicológicos.

0 estudo que será descrito a seguir teve por finalidade aprofundar nessa questão e contribuir, em certa medida, para superar essa polêmica.

\section{Abordagem metodológica}

O estudo baseou-se na realização de entrevistas em profundidade com pacientes que haviam recebido o diagnóstico de fibromialgia, sendo que alguns tiveram um diagnóstico anterior de LER/ DORT, levando ao afastamento do trabalho, e outros foram diagnosticados apenas como fibromiálgicos, não havendo qualquer episódio anterior identificado como LER/DORT, nem envolvendo suas atividades profissionais.

Foram realizadas entrevistas com seis pacientes, todas do sexo feminino. A primeira entrevis- ta foi conduzida com a intenção de coletar o maior número de informações possíveis sobre a evolução do problema de saúde da paciente, desenvolvimento dos sintomas, tratamentos realizados, história pessoal, incluindo uma pesquisa detaIhada sobre o histórico ocupacional. Todas as pacientes consentiram com futuras entrevistas, sefosse necessário. Das seis pacientes, três foram entrevistadas pela segunda vez e uma foi entrevistada três vezes.

Todas as entrevistas foram gravadas com o consentimento das pacientes e transcritas para análise de conteúdo e construção de casos clínicos. Entrevistamos, inicialmente, as três pacientes que tinham diagnóstico de fibromialgia, mas relatavam também um componente de sobrecarga ocupacional em seus quadros, tendo recebido, em algum momento, o diagnóstico deLER/ DORT. Em seguida, realizamos mais três entrevistas com pacientes que tinham diagnóstico de fibromialgia e não apresentavam história de sobrecarga ocupacional. Cabe esclarecer que o total de pacientes dos dois grupos não foi determinado previamente, mas estabelecido após os contatos quando percebemos que os dois grupos estavam bem configurados, sendo desnecessário acrescentar mais sujeitos ao estudo.

\section{Análisedos casos clínicos}

Os casos que compõem nosso estudo foram classificados em dois grupos: 0 de pacientes portadores de fibromial gia com história pregressa de sobrecarga ocupacional (e tendo sido inicialmente diagnosticados como portadores de LER/DORT), e o de pacientes portadores de fibromial gia sem história pregressa de sobrecarga ocupacional e, portanto, sem diagnóstico anterior deLER/D ORT.

O primeiro grupo foi constituído por três mulheres, cujos sintomas caracterizados como decorrentes da fibromialgiativeram seu início no contexto ocupacional, sendo, em um primeiro momento, diagnosticados como LER/D ORT. Uma dela é dentista e as outras duas sempre trabalharam como secretárias. A dentista exercia como principal atividade, no período do surgimento dos sintomas, a moldagem de próteses removíveis e as duas secretárias realizavam diversas atividades, mas com predomínio da digitação. Ambas as secretárias apresentaram um quadro inicial típico de LER/DORT, e, após algum tempo, desenvolveram sintomas que preenchem os critérios de diagnóstico para a fibromialgia. No caso da dentista, a dor apresentou- 
se, inicialmente, no polegar direito e logo irradiou-se para esse membro superior e pescoço, $e_{\text {, }}$ em seguida, também para o membro superior esquerdo. Apesar de, posteriormente, essa paciente também ter apresentado outros sintomas que compõem a síndrome da fibromialgia, suas dores e pontos dolorosos se localizaram apenas na metade superior do corpo. Essa apresentação "menos típica" dos sintomas poderia ser classificada como uma "forma regional" de fibromialgia, que, segundo Reilly', é uma ocorrência comum, apesar do ACR estabelecer como critério decisivo a dor nos lados direito e esquerdo do corpo e acima e abaixo da cintura.

A pacientequetrabalhava como dentistatambém recebeu, em um primeiro momento, o diagnóstico de LER, que Ihe foi omitido. Ela tomou conhecimento deste fato apenas quando, no processo de afastamento, teve acesso ao seu prontuário para documentar a evolução dos seus sintomas. Sua história ilustra bem algo que tende a tornar-se cada vez mais comum: o uso do diagnóstico de fibromial gia como forma de se descaracterizar o nexo entre os sintomas e o trabalho, em situações nas quais o exercício da atividade profissional éo principal fator etiológico.

As duas pacientes que atuaram como secretárias também têm uma história pregressa de sobre carga ocupacional e, embora preencham os crité rios do ACR para o diagnóstico da fibromialgia, apresentam uma história em que é evidente um quadro inicial característico de LER/DORT. Ambas iniciaram os sintomas realizando um trabalho cuja principal atividade era a digitação, além de submetidas a condições inadequadas, sobretudo do ponto de vista ergonômico. Esse aspecto, segundo Assunção e Rocha ${ }^{18}$, pode promover estresse físico e psíquico: $\mathrm{Na}$ atividade de digitação, além do estresse e da tensão psíquica decorrentes da organização do trabalho, observa-se que o mobiliário (cadeira emesa) nem sempreapresenta as regulagens necessárias que garantam a sua adequação à diversidade anatômica dos seres humanos; o teclado ea tela, muitas vezes fixos, levam a posturas contraídas; éfrequentea presença de reflexos causados pelo iluminamento inadequado e tela sem filtro antirreflexo e os documentos nem sempre são legíveis. As lesões por esforços repetitivos (LER) são consequência dessa forma de trabalho, onde os trabalhadores submetidosa um trabalho que não éorganizado por eles epara eles, esim pela lógica da produção capitalista, se expõem a: posto de trabalho inadequado, ambiente desfavorável (ruído e iluminamento), movimentos repetitivos em alta velocidade, tensão e estresse oriundos da organização de trabalho.
A coexistência dos dois diagnósticos pode ser explicada pela ocorrência concomitante e coincidentede duas entidades nosológicas distintas, pelo desenvolvimento da fibromialgia a partir de uma forma "regional" de apresentação da doença, ou pelo surgimento de duas patologias em decorrência de um mesmo fator etiológico, no caso, a sobrecarga gerada pelo trabalho. Podemos pensar ainda na possibilidade de evolução de um quadro de LER/DORT para um de fibromialgia.

Os sintomas das LER/DORT, apesar de, inicialmente, apresentarem-sedeformainsidiosa, predominando mais no término ou em momentos de picos de produção nos contextos de trabalho, aliviam através do repouso. Com o decorrer do tempo, eles podem tornar-se frequentes durante toda a jornada, e também no exercício de outras atividades. N esse momento, em geral, as pessoas procuram atendimento médico, devido às dificuldades que tais sintomas implicam no uso de suas capacidades funcionais. É comum, a partir daí, o tratamento baseado apenas em antiinflamatórios e sessões de fisioterapia, o que somente irá camuflar o problema sem atingir suas causas, caso não seja acompanhado de alterações nas condições e organização do trabalho. Com o passar do tempo, os sintomas, além de aparecerem espontaneamente, tendem a se manter de forma contínua, gerando crises dedor intensa, geralmente desencadeadas por movimentos bruscos, ou mesmo pequenos esforços físicos, alternância detemperatura, insatisfação e tensão ${ }^{19}$. Quando o paciente se encontra nesse grau de evolução das LER/ DORT, geralmente tem a "obrigação" de comprovar a existência da doença, para justificar sua limitação ou incapacidade laborais.

$\mathrm{M} \mathrm{el}^{20}$ realizou um estudo sobre as condições do exercício profissional do médico perito da previdência social, no qual constata essa necessidade de comprovação do diagnóstico por parte do paciente: Aparentemente, o perito espera que o segurado demonstre, de forma inequívoca, sua condição de incapacidade, ou seja, apresente objetivamente comprovação que provoque nele, médico perito, convicção a respeito da condição alegada pelo segurado. [...]. O bservou-se, entre os médicos peritos estudados, que a decisão médicopericial é percebida como sendo semelhante a um julgamento: "todo mundo apresenta as provas, as provas verbais e as provas concretas escritas, daquilo que se está pleiteando". ${ }^{20}$

0 processo de instalação e evolução das LER/ DORT, descrito acima, está bem delineado no caso das pacientes do nosso grupo de portadores de fibromialgia com história pregressa de sobrecar- 
ga ocupacional, explicitando a condição prévia ou concomitante do acometimento por LER. Além desse processo ser insidioso, observamos nas histórias de duas dessas pacientes a postergação em procurar 0 atendimento médico, justificada pelo medo de perder o emprego. Em seu estudo, Oliveir ${ }^{19}$, diante de observações semelhantes, coloca uma questão: "Serão as LER/DORT uma doença do medo ou agravadas pelo mesmo?". A autora observa ainda, nos relatos dos seus pacientes, formas de relacionar-se com o trabalho, que também se aplicam aos casos aqui analisados, como uma grande dedicação às suas tar efas.

A limitação funcional das pacientes portadoras de fibromialgia com história de sobrecarga ocupacional ocasionou um período de afastamento, após o qual, com exceção de uma delas que se aposentou, tiveram que retornar ao trabalho. Apesar de 0 afastamento propiciar uma maior disponibilidade de tempo para o tratamento, a readaptação ao trabalho nem sempreéfácil, podendo consistir "num processo angustiante, devido à situação de desvio de função" ${ }^{19}$. Esse aspecto se confirmou nos dois casos de retorno ao trabalho observados em nosso estudo. Em um deles, foi exigida uma adequação a uma situação de trabaIho que, a princípio, gerou perda de autonomia e perda do reconhecimento profissional por assumir função menos valorizada social e institucionalmente. Somente quando buscou uma nova formação, que Ihe permitiu realizar atividades mais condizentes com seus interesses e sem sobrecarga dos membros afetados, é que conseguiu readaptar-se ao trabalho de maneira satisfatória. No outro caso, após seu afastamento, continuou exercendo a mesma função, com poucas alterações nas condições e na organização do seu trabalho, o que tem sido fonte de muito sofrimento.

0 segundo grupo de pacientes do nosso estudo é constituído por mulheres cujo quadro de fibromialgia não apresentou relação com o trabalho. Durante as entrevistas com essas pacientes, preocupamo-nos em explorar minuciosamente todos os tipos de atividades por elas de senvolvidas, a fim de excluir qualquer possibilidade de sobrecarga física, como ocorreu no outro grupo. Constatamos que elas compõem 0 que poderíamos chamar de "perfil típico" dos portadores de fibromial gia, preenchendo os critérios do ACR e excluindo do seu diagnóstico outra patologia reumática e laboral. Ao contrário do que ocorreu no grupo anterior, todas as pacientes deste grupo apresentaram uma história familiar de fibromialgia, o início precoce dos sintomas, que surgiram ainda durante a adoles- cência, ea clara associação entreeventos emocionalmente fortes ou traumáticos com um período de piora significativa dos sintomas.

\section{Consideraçõesfinais}

Diante das diferenças tão evidentes constatadas entre os dois grupos, uma nova questão nos parece inevitável: aquele paciente cujo quadro foi precedido pelo acometimento de LER/DORT, e cuja evolução é tão distinta da forma típica descrita pelo ACR, pode ser considerado como portador da fibromialgia, ou estaríamos lidando com outra entidade nosológica?

$\mathrm{N}$ ão temos ainda uma resposta definitiva para essa questão, mas, desde já, defendemos o reconhecimento da doença ocupacional, ainda que o paciente seja considerado como portador de uma forma "regional" ou "atípica" da fibromialgia, desdequefique estabelecido o nexo com suas condições de trabalho.

Sabemos que vários aspectos são considerados como fatores etiológicos da fibromialgia; sendo assim, tal condição não pode ser atribuída a uma única causa. Segundo Maeda et al. ${ }^{21}$, a síndrome pode iniciar-se após infecção viral ou bacteriana, um acidente, problemas emocionais que envolvam perdas ou conflitos, levando-se a pensar em uma provável falha de adaptação ou incapacidade de laborar respostas adequadas aos estímulos internos e/ou externos. Esses autores realizaram um estudo com 42 pacientes portadores de fibromialgia e constataram que todos os indivíduos do estudo possuíam uma história de vida marcada por sofrimentos, conflitos e perdas. Ou seja, todos relataram situações marcantes, geradoras de "estresse", em até cinco anos antes do aparecimento da doença. Segundo eles, esses pacientes "possuem uma situação de perda ou conflito a qual não souberam enfrentar"21.

Nosso estudo revelou também a presença desses fatores de forte impacto emocional entre as pacientes portadoras de fibromialgia, sem sobrecarga ocupacional. Ou seja, todas elas associaram a piora dos sintomas com situações emocionalmentedifíceis quevivenciaram. Quanto às pacientes do outro grupo, constatamos também dificuldadese perdas importantes, mastalvez a pior delas tenha sido a perda da saúde quando foram acometidas por LER/DORT. Poderíamos, então, pensar que essa situação atuou como uma espécie de "detonador" do quadro defibromial gia queseconfigurou, em seguida? Se isto é verdade, como éque se daria a passagem entre as duas condições? 
São perguntas ainda sem respostas satisfatórias, embora alguns pesquisadores apresentem evidências importantes sobre uma provável relação entreos dois quadros. Riberto ${ }^{10}$, por exemplo, observou que, apesar da controvérsia existente na literatura a respeito da relação da fibromialgia com eventos traumáticos, e do desconhecimento dos mecanismos pelo qual o trauma pode desencadear a fibromial gia, tanto os traumas físicos como os emocionais têm sido relacionados com o surgimento de dor generalizada. Segundo ele, não éraro que os pacientes relacionem seus sintomas a situações específicas de "estresse emocional" ou sobrecarga do aparelho locomotor, ao serem submetidos, por exemplo, a esforços, repetições, posturas inadequadas ou lesão direta dos ossos e partes moles. A ocupação exercida pelo paciente foi admitida como fator etiológico pelo autor, independente do nexo ter sido estabelecido pela perícia do INSS, sendo considerada como uma possível causa dos traumas citados, juntamente com experiências de agressão ou lesão física. Assim, entre os pacientes portadores de fibromial gia de origem traumática, o trabalho representou $77,9 \%$ entre os fatores etiológicos.

Ao revisar a literatura e considerar os fatores traumáticos, em especial aqueles relativos ao trabalho, na etiologia da fibromialgia, o estudo de Riberto ${ }^{10}$ nos remete novamente a uma problemática que já esteve presente nas discussões sobre LER, e hoje está posta no que concerne à fibromialgia: o reconhecimento dessa patologia como doença ocupacional.

As mudanças recentemente introduzidas no mundo do trabalho, sobretudo as inovações tecnológicas, trouxeram grandes alterações no modo detrabalhar e, consequentemente, de adoecer dos trabal hadores. O bserva-se uma tendência à multi plicação de transtornos mentais, mas também de problemas essencialmente físicos, como as doenças osteomusculares.

A caracterização da doença ocupacional, embora estabelecida nos serviços de saúde, em última instância é determinada pelo IN SS, que definirá o "benefício" ao qual fará jus o trabal hador. Muitos casos de LER/DORT não têm sido reconhecidos pelo INSS como sendo de origem ocupacional, mesmo diante de evidências das implicações do trabalho no desencadeamento das mesmas. Vimos que os usuários devem comprovar 0 nexo causal com o trabal ho perante o INSS, pois os laudos fornecidos pelos seus médicos não são aceitos pela perícia médica do IN SS. A solicitação de exames complementares aparece, então, como uma tentativa de dar visibilidadeà doença. Entretanto, os resultados pouco conclusivos podem levar à exclusão do diagnóstico de LER/DORT, embora se saiba da existência de casos não detectados em imagens. De acordo com O liveira ${ }^{19}$, devemos atentar que ao realizar exames para a comprovação do diagnóstico, estamos nos submetendo a trabalhar conforme a ótica da perícia médica do IN SS, não validando a clínica da doença. Cabemencionar que uma investigação criteriosa do ambiente de trabalho é uma alternativa possível para o reconhecimento da doença.

Essa falta de visibilidade da doença, constatada nos casos de LER/DORT, é ainda mais frequente na fibromialgia que, mesmo em graus avançados, não é detectada por nenhum tipo de exame laboratorial ou de imagem. Quando esse paciente é encaminhado para afastamento e é submetido a exames periciais no INSS, conta apenas com as suas queixas ehistória clínica para que seja determinado o diagnóstico e, quando for o caso, o nexo de causalidade com o trabaIho. Como esse nexo ainda não está claramente estabelecido, sendo o trabalho apontado apenas em al guns estudose, em outros totalmente rejeitado, o diagnóstico de fibromialgia é utilizado muitas vezes, com a finalidade de desvincular 0 quadro da atividade profissional, conforme ficou claramente evidenciado no nosso estudo.

É importante ressaltar quenão é nossa intenção desconsiderar a multiplicidade dos fatores etiológicosenvolvidosnessa patologia, esim destacar que, em vários casos, o trabalho se apresenta como um fator importante, senão o mais importante, no desencadeamento do problema. N esses casos, vemos uma nítida caracterização de um quadro de LER/DORT, a princípio, e, com o passar do tempo, os sintomas se generalizam, caracterizando uma síndrome que tem sido identificada como fibromialgia. Não se sabeainda como se dá essa "passagem" das LER/D ORT para a fibromialgia, nem se pode afirmar que as primeiras deixam de existir para dar lugar à segunda, pois muitas vezes o que se observa éuma coexistência das duas condições. M as o que parece certo para alguns estudiosos do assunto - e nosso estudo confirma - é que essa síndrome pode ter sua origem nos contextos patogênicos de trabalho.

Sabemos que a inclusão da fibromialgia entre as patologias ocupacionais poderá trazer repercussões para o sistema previdenciário, já em crise no nosso país. Entretanto, é justo que o trabalhador receba 0 atendimento e 0 suporte necessários, uma vez que as condições e ambientes de trabalho, embora aparentemente mais 
confortáveis, têm acarretado um considerável aumento do desgaste físico e emocional dos assalariados. M endes e Dias ${ }^{22}$ publicaram um artigo de revisão sobre a evolução da medicina do trabalho, observando que as mudanças ocorridas com a utilização das novas tecnologias, através da automação e informatização nos processos de trabalho, apesar do aparente conforto que oferecem, na verdade têm acarretado novos riscos à saúde. Segundo eles, tais inovações acabaram gerando doenças de difícil diagnóstico etratamento, dentre elas as LER/DORT.

O campo da saúde ocupacional tem como objeto de estudo a saúde-doença e a sua relação com o trabal ho, buscando compreender os processos de adoecimento aos quais estão expostos os trabalhadores. Considerando a relação da sobrecarga no trabal ho com a fibromialgia evidenciada em nosso estudo, enten demos que essa síndrome deva ser abordada também por esse campo de conhecimento, não ficando restrita à esfera da reumatologia ou da "psicossomática".

Infelizmente, a consolidação da saúde do trabal hador como um campo de conhecimento não tem sido suficiente para garantir aos que sofrem al guma doença ocupacional 0 acolhimento adequado. Pelo contrário, o que vimos neste estudo e também na literatura sobre 0 assunto é um processo no qual impera a lógica do capital, descartando o trabalhador quando este não mais produz no ritmo desejado. A partir daí, instaura-se uma verdadeira luta para provar que a sobrecarga imposta pelo trabalho foi a causa do problema. As lacunas na legislação abrem espaço para que o perito, muitas vezes, desconsidere o laudo de profissionais que acompanham o desenvolvimento do quadro clínico do paciente.

É, portanto, em um contexto no qual a própria lei éindefinida enão se pronuncia demaneira coerente em relação ao assunto, que o perito realiza o seu trabalho e dá o "veredicto" final ao paciente: aposentadoria ou retorno ao trabalho. Entre as pacientes do nosso estudo, uma demorou seis anos para ter seus direitos garantidos. Durante esse período, recebeu alta por duas ve zes e entrou novamente com o pedido de benefício, finalmente concedido. Sua história ilustra a falta de critérios para o reconhecimento do nexo causal com o trabal ho em um quadro em que tal nexo pareceu-nos claramente configurado. Outra não chegou a ser encaminhada para o INSS por que está vinculada à Polícia Militar. No entanto, durante o período de um ano no qual ficou afastada, passou por perícias da PM nas quais, inicialmente, o diagnóstico da fibromial- gia também foi utilizado como uma descaracterização do nexo com o trabalho, sendo, posteriormente, reconhecido. Ao final desse período, quando teria então que ser encaminhada para 0 INSS para aposentar-se, retornou ao trabalho em desvio de função. O utra, ainda, ficou afastada do trabalho por cinco anos com diagnóstico de LER, quando, então, foi diagnosticada como portadora de fibromialgia, recebeu alta do INSS e retornou ao trabalho. 0 nexo causal entre seu quadro clínico e o trabalho, embora admitido durante todo o período de afastamento, passou a ser negado, e, assim, ela retornou para a mesma função exercida anteriormente, só que em condições ainda piores. Cabe ressaltar que essa paciente foi afastada em 1997, período em que a instituição previdenciáriajá passava por mudanças, sem que isso, no entanto, impedisse o reconhecimento das LER/DORT. M as quando foi obrigada a retornar ao trabal ho e teve seu diagnóstico subitamente modificado para fibromial gia, as regras para acesso aos benefícios, estabelecidas pela previdência social, tinham se tornado mais rigorosas, conforme atesta $\mathrm{M} \mathrm{elo}^{20}$ : Das Caixas deA posentadorias ao Instituto $\mathrm{N}$ acional do Seguro Social, existe um trajeto de transformações institucionais, de avanços e recuos no estabelecimento dos direitos sociais que refletem a própria organização social e os conflitos estruturais presentes na sociedade brasileira e em seu modelo político. [...] A instituição previdenciária vem sofrendo alterações, especialmente a partir da década de 90 , reflexos das reformas de Estado [...]. Além disso, observa-se maior rigor para 0 acesso aos ben efícios através do aumento de exigências para a concessão.

Essas reformas estabeleceram critérios que praticamente inviabilizaram o reconhecimento pericial das doenças profissionais, o que culminou em um processo no qual as LER/DORT, apesar de presentes no cotidiano dos trabalhadores, tivessem sua incidência diminuída para o INSS. Atribuímos a isto a mudança no tratamento dado à paciente citada acima, isto é, a negação súbita do nexo de sua doença com o trabal ho, em 2002, além da mudança do seu diagnóstico para fibromialgia e do seu retorno à antiga função. Embora sua história revele com clareza o nexo entre seu adoecimento e o trabalho, ela aguarda, hoje, a decisão da justiça, na tentati va de prová-lo. Enquanto isso, sai de sua casa todos os dias para realizar atividades que só contribuem para piorar seus sintomas.

Diante do que foi exposto, fica evidente que estamos diante de uma temática que envolvequestões que vão além das dimensões clínicas, alcan- 
çando um patamar essencialmente político. Ape sar de todo o problema em torno dos critérios diagnósticos da fibromial gia, a maioria dos mé dicos, dos profissionais da área de saúde, e dos próprios pacientes, já se referem a ela como uma entidade nosológica distinta, cujos sintomas já são conhecidos. Embora em muitos casos os tratamentos sejam pouco eficazes, o reconhecimento da doença possibilita aos pacientes estabelecer uma conduta que Ihes permite conviver melhor com o seu quadro. Por outro lado, o sistema previdenciário, as empresas e a própria comunidade médica parecem despreparados para o re conhecimento e o tratamento dos aspectos ocupacionais, tanto da fibromialgia, quanto das LER/ DORT. No confronto com a tríade políticas de saúde-empresários-médicos, o pacientetem sido visto como aquele que apresenta queixas inexis- tentes ou que pretende obter ganhos secundários com seu problema. Além disso, frequentemente, ao invés de se preocupar com as dores equeixas desses pacientes, passa-se a discutir se essas entidades nosológicas realmente existem. Sabemos que 0 avanço em relação aos critérios diagnósticos é fundamental nas duas condições; entretanto, enquanto isso não chega a termo, independente da designação da doença, LER/DORT ou fibromialgia, não se pode ignorar que existem muitas pessoas sofrendo e que boa parte delas tem seus sintomas claramente vinculadosà sua atividade profissional. 0 reconhecimento do seu caráter ocupacional permitirá que se adotem medidas preventivas adequadas nos locais detrabalho, além de oferecer aos que já foram atingidos pelo problema o apoio necessário para seu enfrentamento.

\section{Colaboradores}

TT Álvares trabalhou na concepção e redação final deste artigo, na pesquisa e coleta de dados. M EA Lima orientou a pesquisa e dissertação de mestrado que deu origem a este artigo, e trabaIhou na concepção do mesmo. 
Referências

1. Provenza JR, Pollak DF, Souza EJR, Paiva ES, Matos JM C, H elfenstein M, Heymann RE. Diretrizes para o Diagnóstico e Tratamento da Fibromialgia. Rev Bras Reumatol 2004; 44(1):S49-S59.

2. Wolfe F, Smythe HA, Yunus M B et al. The American college of rheumatology 1990 criteria for the classification of fibromyalgia: Report of the multicenter criteria committee. Arthritis Rheum 1990; 33(2):160-172.

3. Haun MVA, Ferraz MB, Pollak DF. Validação dos critérios do Colégio Americano de Reumatologia (1990) para classificação da fibromialgia, em uma população brasileira. Rev Bras Reumatol 1999; 38(4):221-231.

4. Pridmore $S$, Rosa MA. Fibromialgia para o psiquiatra. Rev Psiq Clin 2002; 29(1):33-41.

5. Silva LC, Abreu AC, Pelegrino OS, Coelho OS. 0 valor da contagem de pontos dolorosos no diagnóstico clínico da fibromialgia. Rev Bras Reumatol 1997; 37(6):317-322.

6. Reilly PA. Fibromyalgia in the workplace: a 'management' problem. Annals of the Rheumatic Diseases 1993; 52:249-251.

7. Waylonis GW, Ronan PG, Gordon C. A profile of fibromyalgia in occupational environments. Am J Phys M ed Rehab 1994; 73(2):112-115.

8. Helfenstein $M$, Feldman $D$. The pervasiveness of the illness suffered by workers seeking compensation for disabling arm pain. JOEM 2000; 42(2):171-175.

9. Wolfe F. Post-traumatic fibromyalgia: a case report narrated by the patient. Arthritis Care and Research 1994; 7(3):161-165.

10. Riberto M. Comparação das manifestações clínicas em pacientes portadores de fibromialgia traumática e nãotraumática [dissertação]. São Paulo (SP): Faculdade de M edicina, Universidade de São Paulo; 2004.

11. Paiva ES, Deodhar A, Jones KD, Bennett R. Impaired growth hormone secretion in fibromyalgia patients. Arthritis Rheum 2002; 46:1344-1350.

12. Pillemer SR, Bradley LA, Crofford LJ, Moldofsky $H$, Chrousos GP. The neuroscience and endocrinology of fibromyalgia. Arthritis Rheum 1997; 40(11):1928-1939.

13. Yunus MB. Towards a Model of Pathophysiology of Fibromyalgia: Aberrant Central Pain M echanisms with Peripheral Modulation. The Journal of Rheumatology 1992; 19(6):846-850.

14. Brasil. Instituto Nacional do Seguro Social. Ordem de Serviço IN SS/DSS no 606, de 5 de agosto de 1998. Aprova Norma Técnica sobre Distúrbios Osteomusculares Relacionados ao Trabalho - DORT. Diário Oficial da União 1998; 19 ago.
15. Verthein MAR, Gomez CM. As armadilhas: bases discursivas da neuropsiquiatrização das LER. Cien Saude Colet 2001; 6(2): 457-470.

16. Littlejohn G. Medicolegal aspects of fibrositis syndrome. Journal of Rheumatology 1989: 16(19)169-173.

17. Helfenstein $M$, Feldman D. Prevalência da síndrome da fibromialgia em pacientes diagnosticados como portadores de lesões por esforços repetitivos (LER). Rev Bras Reumatol 1998; 38(2):71-76

18. Assunção $A A$, Rocha LE. Agora... até namorar fica difícil: uma história de lesões por esforços repetitivos. In: Buschinelli JT, Rocha LE, Rigotto RM, organizadores. Isto é trabalho de gente? Vida, doença e trabalho no Brasil. Petrópolis: Vozes; 1994. p.461-493.

19. Oliveira RMR. A abordagem das Lesões por Esforços Repetitivos/Distúrbios Osteomusculares Relacionados ao Trabalho - LER / DORT no Centro de Referência em Saúde do Trabalhador do Espírito Santo - CRST/ES [dissertação]. Rio de Janeiro (RJ): Escola Nacional de Saúde Pública, Fundação Oswaldo Cruz; 2001.

20. M elo M PP. Condições do exercício profissional do médico perito da previdência social [dissertação]. Belo Horizonte (M G): Faculdade de M edicina, Universidade Federal de M inas Gerais; 2003.

21. M aeda AM C, Fernandez MIG, Feldman D. Compreendendo a "Dor Psíquica" dos portadores de Fibromialgia. [site da Internet]. [acessado 2005 out 16] Disponível em: http://www.fibromialgia.com.br/ novosite/index.php?id_rel_value $=\& i d \_r e l=\&$ modulo $=$ medicos_artigos $\& i \bar{d} \_$mat $=14 \& i \bar{d} \_$mat_ mat $=343$

22. M endes $R$, Dias EC. Da medicina do trabalho à saúde do trabalhador. Rev. Saude Publica 1991; 25 (5):341-349.

Artigo apresentado em 18/03/2007

Aprovado em 13/12/2007 